\title{
Direct CO2-to-dimethyl Ether Hydrogenation over CuZnZr/zeolite Hybrid Catalyst: New Evidences on the Interaction Between Acid and Metal Sites
}

\author{
Enrico Catizzone $^{1 *}$, Giuseppe Bonura ${ }^{2}$, Massimo Migliori ${ }^{3}$, Giacobbe Braccio ${ }^{1}$, Francesco Frusteri ${ }^{2}$, Girolamo Giordano ${ }^{3}$ \\ ${ }^{1}$ ENEA-Italian National Agency for New Technologies, Energy and Sustainable Economic Development, Trisaia Research \\ Centre, Rotondella 75026, Italy \\ ${ }^{2}$ CNR-ITAE, Istituto di Tecnologie Avanzate per l'Energia "Nicola Giordano", via S. Lucia Sopra Contesse, 5, Messina \\ 98126, Italy \\ ${ }^{3}$ Deptartment of Environmental and Chemical Engineering, University of Calabria, via P. Bucci, 44a, Rende 87036, Italy
}

Corresponding Author Email: enrico.catizzone@enea.it

https://doi.org/10.18280/acsm.430302

Received: 5 March 2019

Accepted: 20 May 2019

\section{Keywords:}

$\mathrm{CO}_{2}$ recycling, dimethyl ether, heterogeneous catalysis, zeolites, nanostructured catalysts, Lewis/Brønsted acid sites, industrial chemistry processes

\begin{abstract}
The production of DME via one-pot $\mathrm{CO}_{2}$ hydrogenation is a strategic way of recycling $\mathrm{CO}_{2}$ with the production of a high-value added product. This work aims to investigate the effect of the main zeolite features, e.g. structure or acidity, on the activity, selectivity and stability of the catalyst for DME production via both methanol dehydration and one-pot $\mathrm{CO}_{2}$ hydrogenation. Several zeolites (i.e. FER and MFI) were synthesized and deeply characterized with XRD, B.E.T, $\mathrm{NH}_{3}$-TPD and FTIR. Obtained crystals were used as catalysts for methanol dehydration as well as for one-pot $\mathrm{CO}_{2}$-to-DME process. Obtained results allow giving new insights about the role of the interaction between metals and acid sites for an efficient DME production via one-pot $\mathrm{CO}_{2}$ hydrogenation. In particular, zeolite acidity plays a crucial role in methanol dehydration step and Lewis acid sites seems to be more active than Brønsted sites. Furthermore, metal/acid proximity plays are a key factor in one-pot $\mathrm{CO}_{2}$ hydrogenation; in fact, the catalytic performances of multifunctional catalytic bed improve by increasing the metal/acid sites proximity. The findings of this research allow to highlight the main factors to be taken into account in terms of design and optimization of new catalytic systems for DME synthesis.
\end{abstract}

\section{INTRODUCTION}

The continue grow of the world's population and the rapid development of emerging economies cause require in import increase in the worldwide demand of energy. With the evergrowing concern on world environmental pollution the quest for cleaner energy sources is strengthened in order to minimize the impact on the environment. Nowadays, natural gas valorisation represents a reliable way to overtake the other fossil fuel in terms of availability, accessibility, versatility, low cost and a smaller environmental footprint. In this sense, The International Energy Agency (IEA) has estimated that the global demand of natural gas could rise could be set to grow more than $50 \%$ by 2035 , from 2010 levels, especially if gas natural extraction, by both conventional or unconventional route (e.g. shale gas), is joined with a right valorisation of this raw material [1-2]. Production of syngas (mixture of $\mathrm{H}_{2}, \mathrm{CO}$ and $\mathrm{CO}_{2}$ ) by partial oxidation, steam reforming or autothermic treatment of methane or natural gas, represents a highly efficient way to valorise these energy sources with production high value products [3-4]. Indeed, environmental and economic sustainability of important syngas-based industrial processes, as Fischer-Tropsch, Methanol-to-Gasoline, Methanol-toOlefins and ammonia process, is strongly affected by syngas production system. Furthermore, the production of syngas from biomass gasification is a reliable alternative route to strongly increase the sustainability of above-mentioned industrial processes [5-6]. Environmental impact during the utilization of the final product is also an important challenge of modern both academic and industrial research in order to increase sustainability of these energetic sources. In this concern, production of dimethyl ether (DME) from natural gas or biomass permits to obtain an alternative Diesel fuel with a high well-to-wheel efficiency compared with other fuel (i.e. methane, ethanol, and Fisher-Tropsch fuels) and, according with the above mentioned economic and environmental $\mathrm{i}$ aspects, it represents a reliable alternative fuel with very high sustainability [7]. DME has received a growing attention as sustainable alternative fuel for Diesel engines because to its high cetane number $(>55)$ and to the important reduction of $\mathrm{NO}_{\mathrm{x}}$ emissions and total absence of $\mathrm{SO}_{\mathrm{x}}$ and particular matter in flue gases [8], unlike when diesel fuel is used. DME $\left(\mathrm{CH}_{3}-\mathrm{O}-\mathrm{CH}_{3}\right)$, the simplest of the ethers, is a colourless, non-toxic, non-corrosive, noncarcinogenic and environmentally friendly compound with a normal boiling point of $-25^{\circ} \mathrm{C}$ that can be liquefied above 0.5 $\mathrm{MPa}$ at room temperature. Furthermore, DME has chemical and physical properties similar to those of propane and butane, the main constituents of LPG, so it could be distributed, stored and utilized as an LPG substitute without increase of costs [9]. DME can be industrially synthesized in two routes following the indirect or direct synthesis. Indirect synthesis is a two-steps process: the traditional methanol synthesis from syngas $\left(\mathrm{H}_{2}-\mathrm{CO}\right.$ ratio equals to about 2$)$ over $\mathrm{Cu} / \mathrm{ZnO} / \mathrm{Al}_{2} \mathrm{O}_{3}$ (CZA) redox catalyst, in the temperature 
range $240-280{ }^{\circ} \mathrm{C}$ and pressure between 3 and $7 \mathrm{MPa}$ [10], followed by methanol dehydration reaction to dimethyl ether over an acid catalyst. On the other hand, the direct synthesis is a one-step process where the two reactions, methanol synthesis (via CO hydrogenation) and the dehydration to DME, take place in the same reactor under process conditions close to those of methanol synthesis [10]. The one-step route is more efficient than double-step one, mainly because of the thermodynamic advantages in case of simultaneous reactions (with concerted methanol dehydration is possible to increase the extent of reaction of syngas-toalcohol step) but also for the lower processing costs. Valorisation and reusing of carbon dioxide emitted from power station in an important challenge in order to mitigate the growing global warming [11-20]. In this sense, a growing attention is receiving the synthesis of methanol or DME by total or partial substitution of $\mathrm{CO}$ with $\mathrm{CO}_{2}$.

In particular, in the one-pot $\mathrm{CO}_{2}$ hydrogenation process, the DME synthesis net reaction is given by the reaction reported in Eq. (1):

$$
2 \mathrm{CO}_{2}+6 \mathrm{H}_{2}=\mathrm{CH}_{3} \mathrm{OCH}_{3}+3 \mathrm{H}_{2} \mathrm{O}
$$

involving the carbon dioxide hydrogenation to methanol, Eq. (2), and methanol dehydration, Eq. (3).

$$
\begin{aligned}
& \mathrm{CO}_{2}+3 \mathrm{H}_{2}=\mathrm{CH}_{3} \mathrm{OH}+\mathrm{H}_{2} \mathrm{O} \\
& 2 \mathrm{CH}_{3} \mathrm{OH}=\mathrm{CH}_{3} \mathrm{OCH}_{3}+\mathrm{H}_{2} \mathrm{O}
\end{aligned}
$$

DME synthesis reaction is an exothermic reaction that releases about $122 \mathrm{~kJ}$ of heat for each DME mol produced. For this reason, from a thermodynamic point of view, a decrease in reaction temperature should favor the synthesis of DME.

Furthermore, high pressure also should favor DME production since the reaction occurs with a reduction of total moles number [15]. Nevertheless, temperatures above $240{ }^{\circ} \mathrm{C}$ are usually requested for facilitating $\mathrm{CO}_{2}$ activation rate since $\mathrm{CO}_{2}$ is not a highly reactive molecule. On the other side, high reaction temperature favors endothermic side reactions such as reverse water gas shift that consume carbon dioxide and hydrogen producing carbon monoxide and water as reported in Eq. (4):

$$
\mathrm{CO}_{2}+\mathrm{H}_{2}=\mathrm{CO}+\mathrm{H}_{2} \mathrm{O}
$$

Furthermore, hydrocarbons and coke may be formed during such process. The deposition of coke on catalyst surface is well-known cause of deactivation.

Therefore, highly active and selective catalyst is required to avoid the formation of undesired by-product. Anyhow, irrespective of the process applied for the DME synthesis, it has been demonstrated that the properties of the acid matrix significantly affect selectivity and durability of bi-functional catalyst as well as the overall process efficiency, being controlled by the dehydration step [21-22].

Several studies have been carried out using $\gamma-\mathrm{Al}_{2} \mathrm{O}_{3}$ as acid catalyst reporting high selectivity towards DME formation in the temperature range $200-300{ }^{\circ} \mathrm{C}$, but also rapid deactivation by water adsorption on Lewis acid sites, especially during the direct synthesis via $\mathrm{CO}_{2}$ hydrogenation where a lot amount of water is formed from both methanol dehydration and reversewater-gas-shift reaction [23]. So, a more hydrophobic acid catalyst is suggested to be used in this gas-to-liquid reaction. As alternative to $\mathrm{\gamma}-\mathrm{Al}_{2} \mathrm{O}_{3}$, zeolites have been also investigated revealing a better stability to water and higher methanol conversion [24-28].

Activity, selectivity and stability of zeolites applied in acid-catalysed reactions are recognised to depend upon several factors as zeolite structure, acidity and crystal size. Zeolite channel system (channel orientation and opening size) is a well-known factor affecting strongly products distribution and catalyst deactivation [29-38].

Zeolite deactivation in both DME or olefins synthesis is due mainly to coke deposition and catalyst structure and acidity affect strongly mechanism of coke formation and the effect of coke on behaviour of the catalyst overtime. Campelo et al. [39] report a comparison between several silico-aluminophosphate with different channel configuration (1-, 2- and 3-dimensional) and it is showed that on a 3 dimensional structure (as SAPO-34), the oligomers formed in the channel can migrate to the big cage of this structure where react over strong acid sites leading formation of heavier oligomers and aromatics that cannot back to the channel causing a rapid catalyst deactivation for pore blocking. On the other hand, deactivation of 1-dimensional large channel (as SAPO-5) is due to the adsorption of multi branched chains on the strong acid sites causing blocking of the pore system. Structures with both small/medium channels and cages, as MFI type, don't permit trapping of heavy compounds inside the crystal and coke is preferably formed on external surface of crystals and catalyst deactivation occurs by coke deposition on the mouth of the channels [29, 37]. Catalyst deactivation rate is also affected from crystal morphology: small or hierarchical crystals exhibits higher resistance to deactivation by coke deposition than large crystal with microporous textural [34-35]. On small 1-D structures, as MTF, no hydrocarbon pool mechanisms are observed even at high temperature $\left(400{ }^{\circ} \mathrm{C}\right)$ and DME is the only product detected in reactor outstream; nevertheless, this structure exhibits fast deactivation over time [45]. In order to produce DME catalyst structure is a key parameter to inhibit both the hydrocarbon pool mechanism and formation of HCP precursors with the aim to obtain both high selectivity toward DME or stability overtime, respectively. In this concern, this work reports methanol conversion carried out at reaction temperature low enough $\left(<250{ }^{\circ} \mathrm{C}\right)$ to inhibit both hydrocarbon pool mechanism and olefins formation showing that catalyst structure affect strongly coke deposition and deactivation even when only DME is detected as product in reactor out-stream. In this sense, FER-type and MFI-type structure disclosed reliable shape-selectivity towards DME synthesis although more details about the role of acid sites should be better elucidate $[27,29,37,40]$.

Concerning the one-pot $\mathrm{CO} 2$ hydrogenation to DME, the current research is focusing on the development of new catalytic system for and efficient $\mathrm{CO}_{2}$ activation with selective production of DME. Physical mixture of $\mathrm{Cu}-\mathrm{ZnO}$ catalyst with zeolite is the simplest way to obtain a bifunctional catalyst for DME synthesis. Recent works showed that $\mathrm{CZ}-\mathrm{ZrO}_{2} /$ zeolites hybrid grains prepared via coprecipitation method exhibits higher activity even if further efforts are required in order to obtain reliable DME productivities for a future industrial application of this process [27]. Realizing a new catalyst with a high synergy between redox and acid function is a current challenge in this field. The perfect hybrid catalyst should offer a high copper 
dispersion (a high copper surface area), an efficient cooperation between acid sites and metal sites, a high resistance to water and a high resistance to deactivation (e.g. sintering of metals, coke deposition).

Catalytic performances of zeolite-based multifunctional catalyst can be improved by substituting $\mathrm{Al}_{2} \mathrm{O}_{3}$ with $\mathrm{ZrO}_{2}$ or $\mathrm{Ga}_{2} \mathrm{O}_{3}$ suggesting that several parameters have yet to be assessed for catalyst optimization. Also, acid function properties can be tuned in order to improve catalytic performances of hybrid grain. For instance, zeolites crystal size plays an important role in syngas-to-DME process [41] but this aspect is not investigated for $\mathrm{CO}_{2}$-to-DME process. Also new synthesis routes for bi-functional catalyst should be explored (e.g. core shell systems, use of hierarchical zeolites, tailored acid sites location) in order to improve catalytic activity and stability [22]. On the whole, several parameters need to be investigated with the aim to give new insights for the design and the optimization of new catalytic system for one-pot $\mathrm{CO}_{2}$ hydrogenation to DME. In particular, the role played by metal-acid sites cooperation is not totally clear.

In this paper, a step by step optimization of the catalyst for DME synthesis is reported. The effect of zeolite structure and acidity on methanol dehydration reaction step is assessed by comparing catalytic performances of FER- and MFI-type zeolites with different acidity. With this aim, zeolites with FER and MFI structures and different $\mathrm{Si} / \mathrm{Al}$ ratio were synthesized and characterized by $\mathrm{XRD}, \mathrm{N}_{2}$ isotherms adsorption/desorption, $\mathrm{NH}_{3}$-TPD and FT-IR analysis. Methanol dehydration step was carried out in a lab-scale fixed bed reactor equipped with both mass flows and temperature controllers. Once the best catalyst for methanol dehydration has been identified, a multifunctional hybrid grain was prepared by oxalate co-precipitation of $\mathrm{CuZnZr}$ precursors over bare zeolite crystals. The metal/acidic multifunctional catalytic bed configuration was optimized aiming to investigate the role of metal/acid sites proximity on DME productivity during one-pot $\mathrm{CO}_{2}$-to-DME process.

\section{MATERIALS AND METHODS}

\subsection{Synthesis}

In order to assess the effect of zeolite features on the DME synthesis, FER-type and MFI-type zeolites with acidity were synthesized. In particular, the acidity of each zeolite structure was varied adopting different $\mathrm{Si} / \mathrm{Al}$ ratio for the synthesis, i.e. $\mathrm{Si} / \mathrm{Al}$ equals to 10,30 and 60 were adopted for FER-type zeolites and $\mathrm{Si} / \mathrm{Al}$ equals to 15,25 and 50 were adopted for MFI-type zeolites. In particular MFI-type zeolites with different acidity level were prepared using tetrapropyl ammonium bromide (TPABr) as structure directing agent (SDA) by starting from a gel with the following molar composition: $10 \mathrm{Na}_{2} \mathrm{O}-8 \mathrm{TPABr}-100 \mathrm{SiO}_{2}-\mathrm{x} \mathrm{Al}_{2} \mathrm{O}_{3}-$ $2000 \mathrm{H}_{2} \mathrm{O}$, where $\mathrm{x}=1,2$ and 3.3 according to the expected $\mathrm{Si} / \mathrm{Al}$ molar ratio of 15,25 and 50 , respectively. As an example, MFI-type zeolite with $\mathrm{Si} / \mathrm{Al}=25$ was prepared as it follows: $2.7 \mathrm{~g}$ of $\mathrm{NaOH}$ (Aldrich) were dissolved in $119 \mathrm{~g}$ of distilled water. After that, $1 \mathrm{~g}$ of aluminum hydroxide (Aldrich) and $7.1 \mathrm{~g}$ of tetrapropyl ammonium bromide (Aldrich) were added to the former solution. After that, $20 \mathrm{~g}$ of precipitated silica (Silica gel 60, Merck) was slowly added and the resulting gel was stirred at $300 \mathrm{rpm}$ for 1 hour at room temperature. The synthesis gel was therefore transferred in PTFE-lined stainless-steel autoclaves and kept in a static oven at $175{ }^{\circ} \mathrm{C}$ for 5,4 or 2 days for samples prepared with $\mathrm{Si} / \mathrm{Al}$ equals to 15,25 and 50, respectively.

The synthesis of FER-type zeolite with $\mathrm{Si} / \mathrm{Al}=10$ was performed with pyrrolidine (Py) as SDA by adopting the following gel synthesis molar composition: 0.6 Py -0.080 $\mathrm{Na}_{2} \mathrm{O}-0.05 \mathrm{Al}_{2} \mathrm{O}_{3}-1 \mathrm{SiO}_{2}-20 \mathrm{H}_{2} \mathrm{O}$.

In a typical synthesis, 1.69 gr of sodium alluminate and 0.165 gr of $\mathrm{NaOH}$ were disoolved in $39.8 \mathrm{gr}$ of distilled water. $6.3 \mathrm{gr}$ of pyrrolidine (Aldrich) were added dropwise and the gel was stirred for $30 \mathrm{~min} .22 \mathrm{gr}$ of LUDOX AS40 were added dropwise and the gel was stirred for $1 \mathrm{~h}$. The crystallization was carried out in $90 \mathrm{~mL}$ PTFE-lined stainless steel autoclave in tumbling conditions at $20 \mathrm{rpm}$ at $175^{\circ} \mathrm{C}$ for $72 \mathrm{~h}$. Synthesis of FER with gel $\mathrm{Si} / \mathrm{Al}=30$ and 60, named FER(30) and FER(60), respectively, were prepared by using pyridine as SDA. FER(30) was synthesized by adopting the following molar synthesis gel composition: 0.6 Pyridine $0.087 \mathrm{Na}_{2} \mathrm{O}-0.017 \mathrm{Al}_{2} \mathrm{O}_{3}-1 \mathrm{SiO}_{2}-25 \mathrm{H}_{2} \mathrm{O}$.

In a typical synthesis procedure $1.48 \mathrm{gr}$ of $\mathrm{NaOH}$ and 0.89 gr of sodium aluminate are dissolved in $127 \mathrm{gr}$ of distilled water. Therefore, $5.41 \mathrm{gr}$ of pyridine (Aldrich) is added dropwise and the solution. After 30 minutes, $17 \mathrm{gr}$ of fumed silica (Aldrich) is added to the solution. The obtained pasty gel is homogenized using a spatula for 30 minutes. The crystallization was carried out in $150 \mathrm{~mL}$ PTFE-lined stainless-steel autoclave in tumbling conditions at $20 \mathrm{rpm}$ at $165^{\circ} \mathrm{C}$ for 7 days.

Similar procedure is adopted to synthesize ferrierite with gel $\mathrm{Si} / \mathrm{Al}$ of 60 , by adopting the following gel molar composition: 2 Pyridine $-0.058 \mathrm{Na}_{2} \mathrm{O}-0.008 \mathrm{Al}_{2} \mathrm{O}_{3}-1$ $\mathrm{SiO}_{2}-25 \mathrm{H}_{2} \mathrm{O}$.

The crystallization is performed at the same temperature of FER(30) but for 5 days.

All the crystallized samples were separated from mother liquor by vacuum filtration and washed with distilled water until neutral $\mathrm{pH}$ of filtrate was obtained. The solid was dried at $80{ }^{\circ} \mathrm{C}$ for $8 \mathrm{~h}$ and calcined at $550{ }^{\circ} \mathrm{C}$ in air flow with the aim to remove organic molecules. H-form sample was obtained via exchange with $\mathrm{NH} 4 \mathrm{Cl}$ solution and calcined again at $550{ }^{\circ} \mathrm{C}$ in order to eliminate ammonia and to obtain catalyst in acid-form. The obtained $\mathrm{H}$-catalysts were directly used for dimethyl ether synthesis via vapor-phase methanol dehydration. Multifunctional catalysts for one-pot CO2-toDME process was prepared via gel oxalate co-precipitation of CuZnZr nitrate (60/30/10 at. \%) in ethanol solutions over $\mathrm{H}$-form zeolite crystals aiming to obtain a hybrid single grain (SG) with $\mathrm{CZZ/zeolite} \mathrm{with} \mathrm{a} \mathrm{weight} \mathrm{ratio} \mathrm{of} \mathrm{1:1.} \mathrm{More}$ details about the adopted procedure are reported elsewhere [35]. Furthermore, "homogenous" physical mixtures (PM) constituted by a pre-synthesized CZZ catalyst and a selected zeolite with a weight ratio of 1:1 were also realized.

\subsection{Characterization}

All of investigated samples were characterized via XRD with APD 2000 Pro diffractometer with a $\mathrm{Cu} \mathrm{K} \alpha$ radiation $(40 \mathrm{kV}, 30 \mathrm{~mA})$ in the range 2 theta $=5^{\circ}-50^{\circ}$. The morphology of investigated catalysts was evaluated with both scanning and transmission electron microscopy (SEM - FEI model Inspect, TEM- Philips CM12). Textural properties (e.g. total surface area, micropore volume) were estimated by performing N2 adsorption/desorption isotherms at $77 \mathrm{~K}$ with ASAP 2020 (Micromeritics) instrument. Both $\mathrm{NH}_{3}$-TPD and 
$\mathrm{H}_{2}$-TPR analyses were performed according to already published procedures [41].

\subsection{Catalytic tests}

Vapor-phase methanol dehydration was carried out over $\mathrm{H}$-form zeolites in the temperature range $140-200{ }^{\circ} \mathrm{C}$ with a methanol weight hourly space velocity (WHSV) of 4.5 gMeOHh-1 gcat-1, in a lab-scale apparatus described elsewhere [40]. Before each catalytic test, the reactor was purged with nitrogen at $240{ }^{\circ} \mathrm{C}$ in order to remove moisture from the catalyst. The catalytic activity of investigated hybrid catalysts during one-pot $\mathrm{CO}_{2}$-to-DME hydrogenation reaction was investigated in a fixed-bed reactor at $260{ }^{\circ} \mathrm{C}$ and total pressure of $3.0 \mathrm{MPa}$ with a gas hourly space velocity (GHSV) of $8,800 \mathrm{NL} / \mathrm{h} /$ gcat by feeding a mixture with a $\mathrm{CO}_{2} / \mathrm{H}_{2} / \mathrm{N}_{2}=3 / 9 / 1$ molar ratio. Prior to each test, the catalyst was reduced in situ at $300{ }^{\circ} \mathrm{C}$ for $1 \mathrm{~h}$ under hydrogen flow at atmospheric pressure. For both the processes, reactor stream was analyzed by GC equipped with flame ionized detector (FID) and a thermal conductivity detector (TCD).

\section{RESULTS AND DISCUSSIONS}

\subsection{Textural properties}

X-ray powder diffraction patterns reported in Figure 1 reveal that all of synthesized zeolites exhibit high purity and neither amorphous nor other phases (e.g. quartz) are detected. Furthermore, the total absence of background in the range 20-30 2 theta suggests that prepared samples have also a high crystallinity. Moreover, both crystallinity and purity seem not be dependent on the aluminum content. After metal coprecipitation no change on both crystallinity and purity was observed but metal oxide peaks appear (not shown).

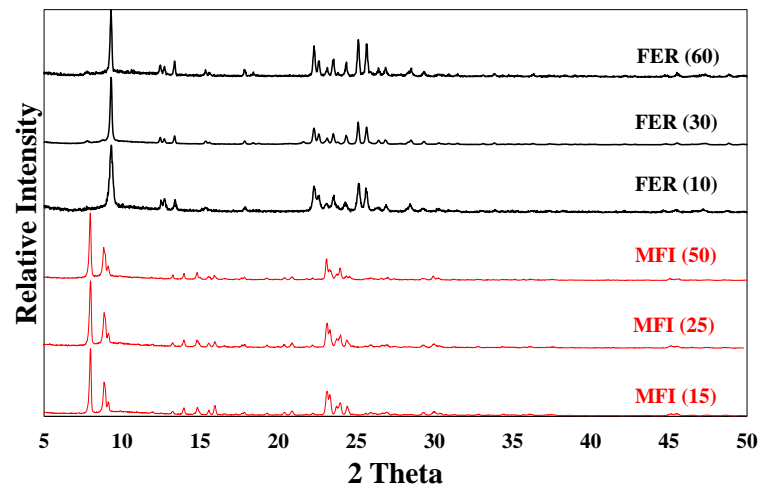

Figure 1. XRD of investigated FER- and MFI-type zeolites

$\mathrm{N}_{2}$ adsorption isotherms carried out at $77 \mathrm{~K}$ are reported in Figure 2. For FER-type zeolite a type a type 1 isotherm is disclosed confirming the microporous structure of zeolites. In particular, FER(10) exhibits a higher nitrogen uptake than FER(30) and FER(60) indicating a higher surface area. Similar isotherms are also observed for MFI-type zeolites with no significant effect of aluminum content. On the other hand, a shoulder is present at $\mathrm{P} / \mathrm{P}^{\circ}$ around 0.2 , typical of MFI-type channel system.

After metal co-precipitation nitrogen uptake strongly reduces and a mesoporosity is generated as revealed by the adsorption/desorption reported in Figure 3 for FER(10)-based catalysts. In fact, the hysteresis loop of FER(10) sample may be related to the plate-like morphology of the crystals [35], that it is different from hysteresis loop observed for CZZ/FER(10) sample, indicating the generation of secondary mesoporosity that may be related to the metallic particles.

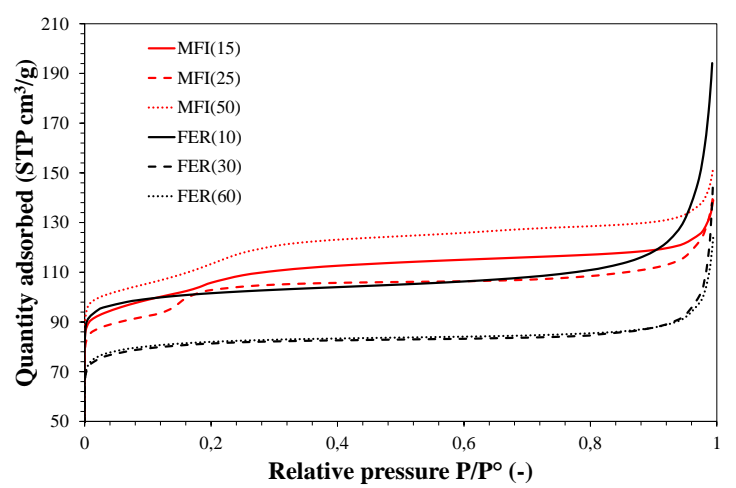

Figure 2. $\mathrm{N}_{2}$ adsorption isotherms of investigated FER- and MFI-type zeolites

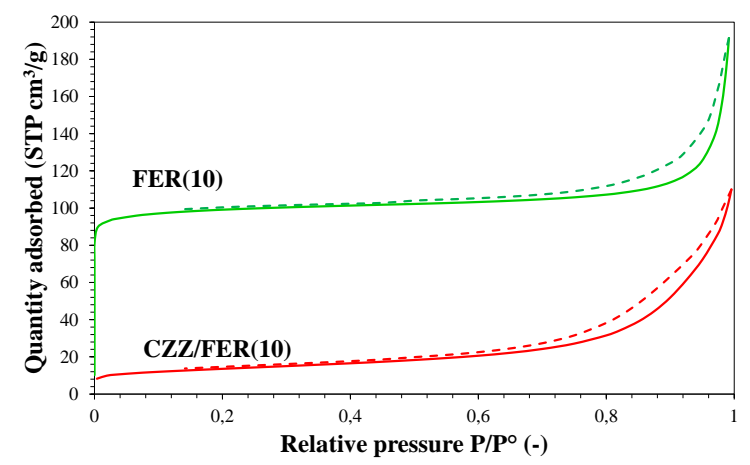

Figure 3. $\mathrm{N}_{2}$ adsorption/desorption isotherms of FER(10) and CZZ/FER(10) sample

The main textural properties of the investigated materials are reported in Table 1. Both total surface area and micropore volume of bare zeolites are in agreement with the value reported in literature for similar materials. According to the isotherms previously discussed, FER(10) exhibits a B.E.T. surface area higher than FER(30) and FER(60), whilst the latter shows almost identical textural properties.

Table 1. Textural properties of investigated materials

\begin{tabular}{cccc}
\hline Sample & $\begin{array}{c}\text { Surface area } \\
\left(\mathbf{m}^{\mathbf{2}} \mathbf{g}\right)\end{array}$ & $\begin{array}{c}\text { Micropore volume } \\
\left(\mathbf{c m}^{\mathbf{2}} / \mathbf{g}\right)\end{array}$ & $\begin{array}{c}\mathbf{d c u}^{\mathbf{3}} \\
(\mathbf{n m})\end{array}$ \\
\hline FER(10) & 332 & 0.126 & - \\
CZZ/FER(10) & 217 & 0.052 & 4 \\
FER (30) & 272 & 0.108 & - \\
FER (60) & 275 & 0.110 & - \\
MFI (15) & 365 & 0.098 & - \\
MFI(25) & 360 & 0.118 & - \\
MFI(50) & 350 & 0.110 & - \\
CZZ & 162 & - & 11 \\
\hline
\end{tabular}

1. Determined by Brunauer-Emmett-Teller equation

2. Determined by t-plot model

3. $\mathrm{Cu}$ average particle size determined by $\mathrm{N}_{2} \mathrm{O}$ chemisorption

After co-precipitation of metals, both surfaces are and micropore volume are strongly reduced, probably due to a partial pore blocking of zeolites due to the presence of CuCnZr particles. $\mathrm{N}_{2} \mathrm{O}$ measurements indicate that smaller copper particles are present on FER-type zeolite suggesting that there is some effect of the presence of zeolite on copper dispersion. 


\subsection{Acidity}

Figure 4 reports the ammonia-TPD profiles as a function of desorption temperature for MFI- and FER-type zeolites, respectively. $\mathrm{NH}_{3}$-TPD profiles allows to assess the strength of acid sites by relating weak acid sites to the ammonia desorbed in the temperature range $100-300{ }^{\circ} \mathrm{C}$ and strong acid sites to the ammonia desorbed at temperature higher than $300{ }^{\circ} \mathrm{C}$. Furthermore, the temperature at which the maximum ammonia desorption occurs may be considered as a parameter of strength of acid sites, even if with same limitations [42]. As the $\mathrm{NH}_{3}$-TPD profiles show, both weak and acid sites are present for both MFI- and FER-type zeolite. For MFI-type zeolite the temperature of maximum ammonia desorption from weak acid sites (WT) increases as aluminum content increases $(\mathrm{MFI}(15)>\operatorname{MFI}(25)>\operatorname{MFI}(50)$ in the range 230-255 ${ }^{\circ} \mathrm{C}$. Similar behavior is exhibited by FER-type zeolites, but WT is in the range $180-230{ }^{\circ} \mathrm{C}$ indicating that FER-type zeolites exhibit weaker acid sites than MFI-type zeolite. On the contrary, both FER- and MFI-type zeolites exhibit similar strength of strong acid sites. Also, for strong acid sites, the maximum temperature of ammonia desorption increases by increasing the aluminum content, passing from $430{ }^{\circ} \mathrm{C}$ to $455{ }^{\circ} \mathrm{C}$. It is important to note a broad band at about $520{ }^{\circ} \mathrm{C}$ for FER(60) sample indicating the presence of a third acid site type with a higher strength.

Table 2 reports the acidity of investigated samples. Considering bare zeolites, total acidity increases accordingly with aluminum content.

In particular, a linear relationship was found between total acidity and $\mathrm{Si} / \mathrm{Al}$ ratio for MFI-type zeolites and $\operatorname{FER}(30)$ and FER(60) zeolites as reported in Figure 5.

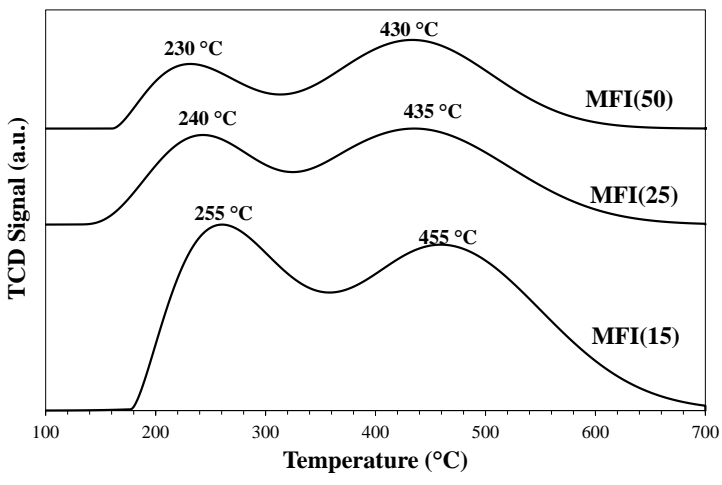

(a) $\mathrm{NH}_{3}$-TPD profiles of MFI-type zeolites

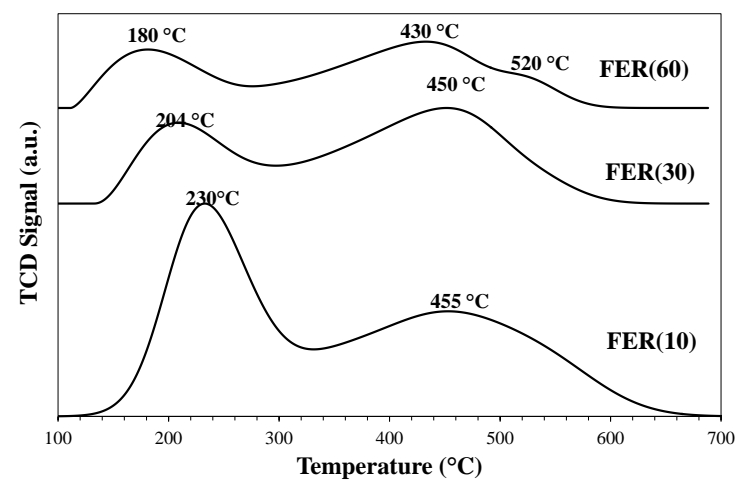

(b) $\mathrm{NH}_{3}$-TPD profiles of FER-type zeolites

Figure 4. $\mathrm{NH}_{3}$-TPD profiles of MFI-type and FER-type zeolites
Table 2. Acidity properties of investigated materials

\begin{tabular}{lccc}
\hline Sample & $\begin{array}{c}\text { Total acidity } \\
(\boldsymbol{\mu m o l} / \mathbf{g})\end{array}$ & $\begin{array}{c}\text { Weak acid } \\
\text { fraction (-) }\end{array}$ & $\begin{array}{c}\text { Strong acid } \\
\text { fraction }(-)\end{array}$ \\
\hline FER(10) & 790 & 0.35 & 0.65 \\
CZZ/FER(10) & 500 & 0.28 & 0.72 \\
FER (30) & 480 & 0.14 & 0.86 \\
FER (60) & 330 & 0.10 & 0.90 \\
MFI (15) & 602 & 0.45 & 0.55 \\
MFI(25) & 515 & 0.42 & 0.58 \\
MFI(50) & 354 & 0.45 & 0.55 \\
\hline 1. Determined from desorbed $\mathrm{NH}_{3}$ in the temperature range $100-700{ }^{\circ} \mathrm{C}$ \\
2. Determined from desorbed $\mathrm{NH}_{3}$ in the temperature range $100-300{ }^{\circ} \mathrm{C}$ \\
3. Determined from desorbed $\mathrm{NH}_{3}$ in the temperature range $300-700{ }^{\circ} \mathrm{C}$
\end{tabular}

On the contrary, FER(10) seems to not follows this trend and it may be related to the presence of large amount of defects (i.e. silanols) may be responsible of part of measured weak acidity [35].

Furthermore, MFI-type zeolites disclose a similar fraction of weak (about $45 \%$ ) and strong sites (about $55 \%$ ). Similar distribution was observed for FER(10).

On the contrary, both FER(30) and FER(60) disclose a higher fraction of strong acid sites (more than $85 \%$ ).

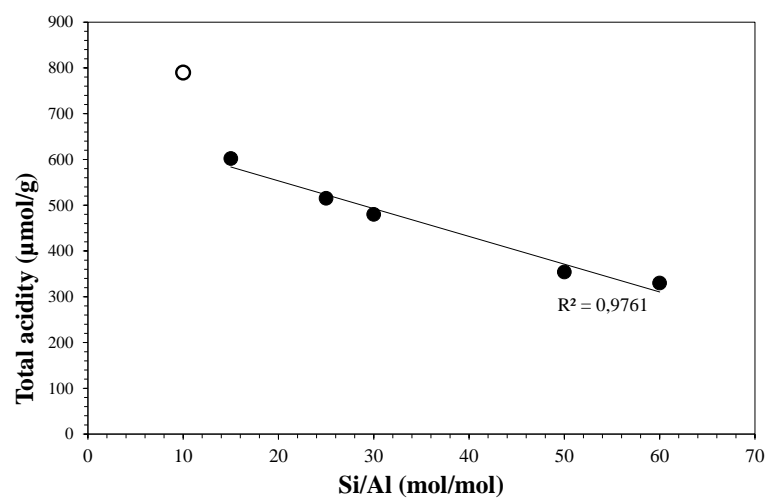

Figure 5. Total acidity as a function of $\mathrm{Si} / \mathrm{Al}$ molar ratio

FT-IR analysis (not shown) carried out with both carbon monoxide and $\mathrm{D}_{3}$-acetonitrile reveals that only $\mathrm{FER}(10)$ possesses Lewis acid sites with a Lewis/Brønsted ratio equals to 0.33 , whilst mainly Brønsted acid sites are present on the other FER-and MFI-type samples.

\subsection{MeOH-to-DME}

Methanol conversion as a function of reaction temperature in the range $140-200{ }^{\circ} \mathrm{C}$ for all of investigated zeolites is reported in Figure 6. In the entire range of temperature only DME was observed with no formation of by-products. Such as olefins or other hydrocarbons.

Methanol conversion increases as the temperature increases according to the Arrhenius's trend as reported in Figure 7.

Apparent activation energies (Eapp) are then calculated and results are reported in Table 3. Eapp values indicate that the activation barrier is always lower for FER-type materials and it decreases as the total acidity increases. Similar trend was followed by MFI-type zeolites.

FER(10) zeolite shows the highest activity in terms of methanol conversion, approaching to the theoretical thermodynamic equilibrium value at the $200{ }^{\circ} \mathrm{C}$. 


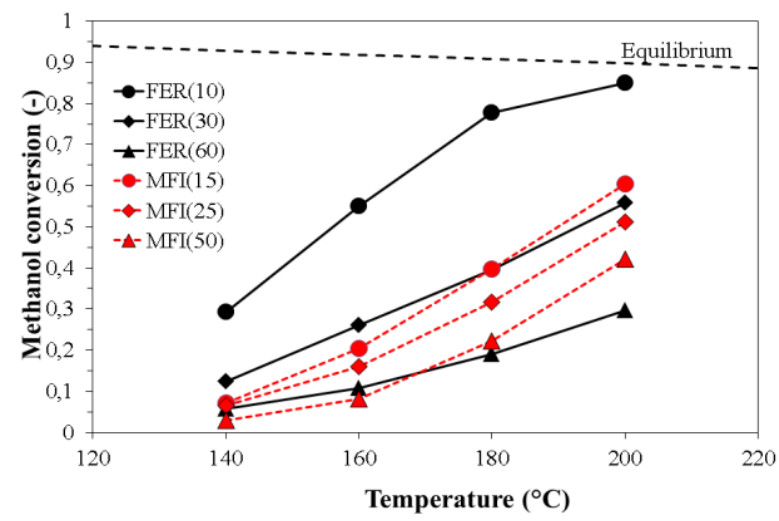

Figure 6. Methanol conversion as a function of reaction temperature for the investigated $\mathrm{H}$-zeolites

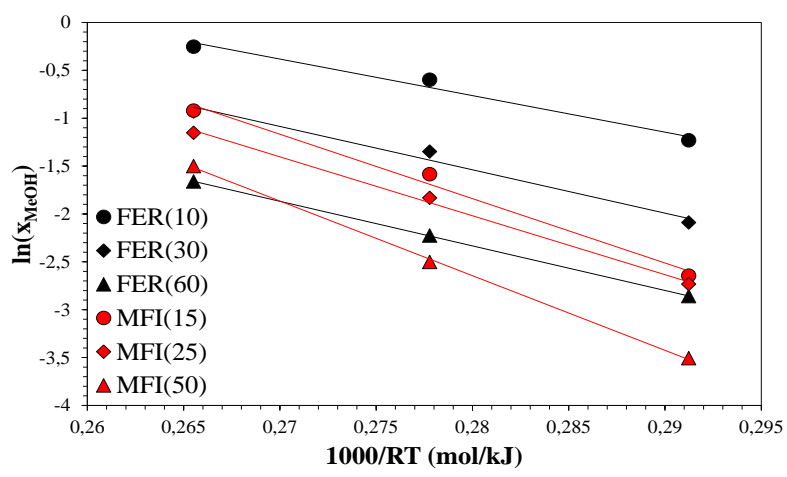

Figure 7. Arrhenius plot

Table 3. Apparent activation energies calculated from Arrhenius plot reported in Figure 8

\begin{tabular}{cccc}
\hline Sample & $\begin{array}{c}\text { Fitting linear } \\
\text { equation* }\end{array}$ & $\boldsymbol{R}^{\mathbf{2}}$ & $\begin{array}{c}\text { Apparent } \\
\text { activation energy } \\
(\mathbf{k J} / \mathbf{m o l})\end{array}$ \\
\hline FER(10) & $\mathrm{y}=-38 \mathrm{x}+9.9$ & 0.980 & 38 \\
FER (30) & $\mathrm{y}=-45 \mathrm{x}+11.1$ & 0.983 & 45 \\
FER (60) & $\mathrm{y}=-47 \mathrm{x}+10.7$ & 1.000 & 47 \\
MFI (15) & $\mathrm{y}=-58 \mathrm{x}+17.1$ & 0.998 & 58 \\
MFI(25) & $\mathrm{y}=-62 \mathrm{x}+15.2$ & 0.998 & 62 \\
MFI(50) & $\mathrm{y}=-78 \mathrm{x}+19.2$ & 0.999 & 78 \\
\hline Note: $\mathrm{y}=$ =ln(methanol conversion); & $\mathrm{x}=1000 / \mathrm{RT}$, & $\mathrm{R}=8.314 \mathrm{~J} / \mathrm{molK}$, \\
T=temperature expressed in K. & &
\end{tabular}

$\mathrm{T}=$ temperature expressed in $\mathrm{K}$.

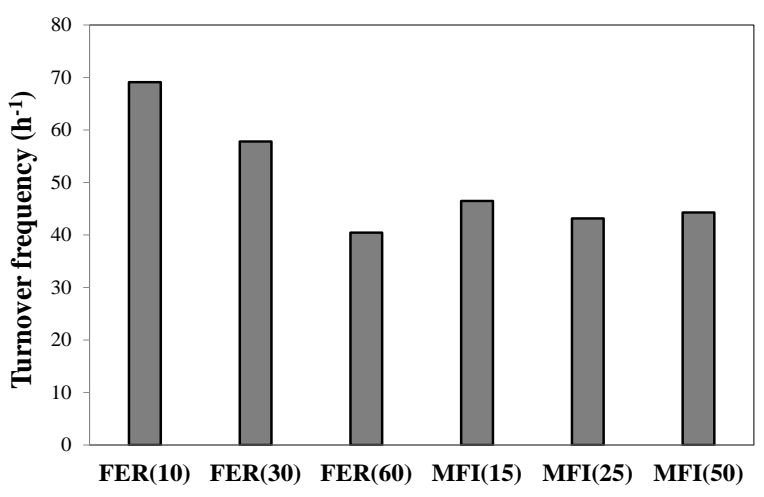

Figure 8. Turnover frequency of methanol-do-dimethyl ether reaction calculated at $180{ }^{\circ} \mathrm{C}$

On the whole, results indicate that catalytic activity during methanol dehydration to DME reaction strongly depends on the acidity of zeolite. In fact, methanol conversion follows the order FER(10)>FER(30)>FER(60) for FER-type zeolites and $\operatorname{MFI}(15)>\operatorname{MFI}(25)>\operatorname{MFI}(50)$ for MFI-type zeolites. On the other hand, although MFI(15) possesses a higher concentration of total acid sites, it shows a lower activity than FER(30) especially at low temperature. Similar behavior is also disclosed for FER(60) and MFI(50) samples. A different trend is observed at temperature higher than $180{ }^{\circ} \mathrm{C}$ as both MFI(15) and MFI(50) exhibit a higher activity than FER(30) and FER(60), respectively.

Such behavior may be related to weak/strong acid sites distribution. In fact, the activity order seems to follow strong acid sites concentration at lower temperature and total acid sites concentrations at higher temperature. In fact, it is reasonable to conclude that mainly strong acid sites are active at lower temperature, whilst weak acid sites became able to catalyze the dehydration of methanol at temperature above or equals to $180^{\circ} \mathrm{C}$. At this temperature turnover frequency may be then calculated and results are reported in Figure 8 . Turnover frequency follows the order

$\operatorname{FER}(10)>\operatorname{FER}(30)>\operatorname{MFI}(15)>\operatorname{MFI}(50)>\operatorname{MFI}(25)>\operatorname{FER}(60)$ revealing that FER(10) and MFI(15) are the most efficient catalysts among the FER-type and MFI-type zeolites, respectively.

\section{4 $\mathrm{CO}_{2}$-to-DME}

As reported in the previous paragraph, FER(10) may be considered as the most active catalyst for methanol dehydration reaction step, among the investigated FER-type and MFI-type zeolites, respectively. Therefore, one-pot $\mathrm{CO}_{2}-$ to-DME reaction was carried out at $260{ }^{\circ} \mathrm{C}$ and 30 bar by using $\mathrm{FER}(10)$ as acid catalyst in three different multifunctional catalytic bed configurations: CZZ-FER(10) dual bed (DB), physical mixture (PM) and hybrid single grain (SG). Figure 9 reports the results of catalytic tests under one-pot $\mathrm{CO}_{2}$ hydrogenation to DME conditions.

$\mathrm{CO}_{2}$ conversion is about $18 \%$ for DB system, and it increases at 20 and $22 \%$ for PM and SG systems, respectively. Catalytic tests carried out over $\mathrm{CZZ}$ reveal a similar $\mathrm{CO}_{2}$ conversion and $\mathrm{CO}$ selectivity observed for $\mathrm{DB}$ system, suggesting that no significant catalytic improvement is obtained when a dual bed is used, highlighting the importance to have an intrinsic cooperation between metallic and acid sites.

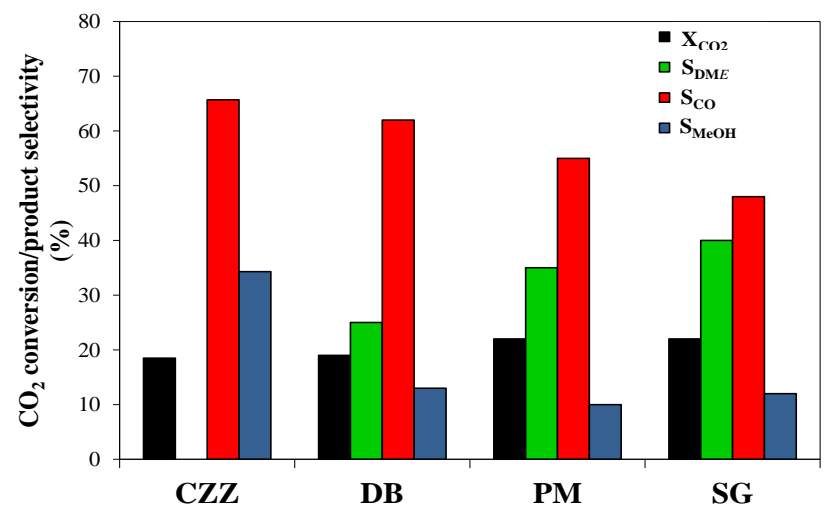

Figure 9. $\mathrm{CO}_{2}$ conversion and selectivity towards DME $\left(\mathrm{S}_{\mathrm{DME}}\right), \mathrm{CO}\left(\mathrm{S}_{\mathrm{CO}}\right)$ and methanol $\left(\mathrm{S}_{\mathrm{MeOH}}\right)$ for the investigated CZZ/FER(10)-DB, -PM and -SG systems and CZZ catalyst $\left(\mathrm{T}_{\mathrm{R}}: 260{ }^{\circ} \mathrm{C}, \mathrm{P}_{\mathrm{R}}: 30\right.$ bar, GHSV: $8800 \mathrm{NL} / \mathrm{h} / \mathrm{g}_{\text {cat }}$ ) 
Moreover, reactor bed configuration also strongly affects product distribution.

DME selectivity is lower for dual bed reactor that exhibits a DME selectivity of $25 \%$, meaning that only $5 \%$ of carbon is converted into dimethyl ether. DME selectivity is increased up to $35 \%$ when both CZZ and FER(10) powders are "homogenously" mixed.

When hybrid single grain is used, catalytic performances are further improved, leading to a DME selectivity of $40 \%$, meaning that more than $10 \%$ of carbon is converted towards the desired product. Such result clearly shows that the efficiency of catalytic bed strongly depends on the possibility to have an intimate interaction between metallic and acid sites. In that sense, hybrid single grain system facilitates the mass transfer between the sites, so promoting a more rapid dehydration of methanol towards dimethyl ether, and brings out the thermodynamic advantages of one-pot process. Therefore, the efficiency of one-pot process is not only related to have the possibility to carried out the reaction in the same reactor unit but also to have a catalytic system with an intimate interaction between the active sites involved in the process.

On the whole, the space-time yield calculated for the investigated system was 732,640 and $395 \mathrm{~g} \mathrm{gME}_{\mathrm{DE}} / \mathrm{h} / \mathrm{kg}_{\mathrm{cat}}$ for SG, PM and DB systems, respectively, again highlighting the crucial role of metal-acid proximity in the synthesis of dimethyl ether. Nevertheless, a gradual deactivation is also observed. In particular, for SG both $\mathrm{CO}_{2}$ conversion and DME selectivity decreases with the time, and after about $40 \mathrm{~h}$ time-on-stream the DME productivity is about 380 $\mathrm{g}_{\mathrm{DME}} / \mathrm{h} / \mathrm{kg}_{\text {cat. }}$. Surprisingly, a higher stability is exhibited by PM system with a final DME productivity of about 450 $\mathrm{g}_{\mathrm{DME}} / \mathrm{h} / \mathrm{kg}_{\text {cat }}$. This behavior may be related to some aspects involving metal/acid proximity. For instance, it may be due to $\mathrm{Cu}+/ \mathrm{H}+$ ion exchange or metal sintering promoted by water on zeolite surface.

\section{CONCLUSIONS}

In this work, FER-type and MFI-type zeolites with different acidity were used as catalysts for DME synthesis via both methanol dehydration and one-pot $\mathrm{CO}_{2}$ hydrogenation. Both zeolite structure and acidity strongly affect catalysis of methanol dehydration. In particular, methanol conversion increases as the acidity increases but the presence of Lewis acid sites seems to favor the reaction. On the whole FER-type zeolite with $\mathrm{Si} / \mathrm{Al}=10$, named $\mathrm{FER}(10)$, exhibits the best performances in terms of DME turnover frequency. Therefore, FER(10) zeolite was also used as acid catalyst for one-pot $\mathrm{CO}_{2}$ hydrogenation to DME coupled with $\mathrm{CuZnZr}$ (CZZ) metallic system. Among several catalytic bed configurations assessed (i.e. dual bed, physical mixture and hybrid single grain), the dual bed reactor resulted to be the less effective configuration, whilst hybrid single grain prepared via gel-oxalate co-precipitation of metal precursors over zeolite crystals exhibited significant better catalytic performance, with a DME productivity of $732 \mathrm{~g}_{\mathrm{DME}} / \mathrm{h} / \mathrm{kg}_{\text {cat }}$, almost doubled than that obtained with double bed configuration. A gradual catalyst deactivation was observed and different phenomena may be the cause of such behavior and further investigation are being performed in order to elucidate that aspect. In particular, future works should be devoted to the study of new multifunctional catalytic systems designed with the aim to improve the cooperation between metal and acid sites but taking into account the role played by mobility of metal particles on the stability. Both sintering and $\mathrm{Cu}^{+} / \mathrm{H}^{+}$ion exchange seems to be the main cause of deactivation of current catalysts during one pot $\mathrm{CO}_{2}$-to-DME process and such aspects need to be better investigated. The onsite water removal (e.g. with membrane reactor) even is a future scenario to be explored.

\section{REFERENCES}

[1] Catizzone, E., Bonura, G., Migliori, M., Braccio, G., Frusteri, F., Giordano, G. (2019). The effect of zeolite features on catalytic performances of $\mathrm{CuZnZr} /$ zeolite hybrid catalysts in one-pot $\mathrm{CO}_{2}$-to-DME hydrogenation. Tecnica Italiana - Italian J. Eng. Sci., 63(2-4): 257-262. https://doi.org/10.18280/ti-ijes.632-420

[2] Olah, G.A. (2005). Beyond oil and gas: The methanol economy. Angew. Chem. Int. Ed., 44(18): 2636-2639. https://doi.org/10.1002/anie.200462121

[3] Wood, D.A., Nwaoha, C., Towler, B.F. (2012). Gas-toliquids (GTL): A review of an industrt offering several routes for monetizing natural gas. J. Nat. Gas Sci. Eng., 9: 196-208. https://doi.org/10.1016/j.jngse.2012.07.001

[4] Aasberg-Petersen, K., Hansen, J.-H.B., Christensen, T.S., Dybkjaer, I., Christensen, P.S., Nielsen, C.S., Madsen, S.E.L.W., Rostrup-Nielsen, J.R. (2001). Technologies for large-scale gas conversion. Appl. Catal. A, 221(1-2): 379-387. https://doi.org/10.1016/S0926-860X(01)00811-0

[5] Perathoner, S., Centi, G. (2014). CO2 recycling: A key strategy to introduce green energy in the chemical production chain. ChemSusChem, 7(5): 1274-1282. https://doi.org/10.1002/cssc.201300926

[6] Molino, A., Migliori, M., Blasi, A., Davoli, M., Marino, T., Chianese, S., Catizzone, E., Giordano, G. (2017). Municipal waste leachate coonversion via catalytic supercritical water gasification process. Fuel, 206: 155151, 2017. https://doi.org/10.1016/j.fuel.2017.05.091

[7] Arcoumanis, C., Bae, C., Crookes, R., Kinoshita, E. (2008). The potential of di-methyl ether (DME) as an alternative fuel for compression-ignition engines: A review. $\quad$ Fuel, 87(7): 1014-1030. https://doi.org/10.1016/j.fuel.2007.06.007

[8] Park, S.H., Lee, C.S. (2014). Applicability of diemthyl ether (DME) in a compression ignition engine as an alternative fuel. Energ. Conv. Manag., 86: 848-863. https://doi.org/10.1016/j.enconman.2014.06.051

[9] Semelsberg, T.A., Borup, R.L., Greene, H.L. (2006). Dimethyl ether (DME) as an alternative fuel. J. Power Sourc., 156(2): 497-511. https://doi.org/10.1016/j.jpowsour.2005.05.082

[10] Azizi, Z., Rezaeimanesh, M., Tohidian, T., Rahimpour, M.R. (2014). Dimethyl ether: A review of technologies and production challenges. Chem. Eng. Process. Proc. Int., 82: 150-172. https://doi.org/10.1016/j.cep.2014.06.007

[11] Sun, J., Yang, G., Yoneyama, Y., Tsubaki, N. (2014). Catalysis chemistry of dimethyl ether synthesis. ACS Catal. 4(10): 3346-3356. https://doi.org/10.1021/cs500967j

[12] Yoon, E.S., Han, C. (2009). A review of sustainable energy - recent development and future prospects of 
dimethyl ether (DME). Comp. Aid. Chem. Eng., 27: 169-175.

7946(09)70249-4

[13] Graves, C., Ebbesen, S.D., Mogensen, M., Lackner, K.S. (2011). Sustainable hydrocarbon fuels by recycling $\mathrm{CO}_{2}$ and $\mathrm{H}_{2} \mathrm{O}$ with renewable or nuclear energy. Renew. Sus. Energ. $\quad$ Rev., $15(1)$ : 1-23. https://doi.org/10.1016/j.rser.2010.07.014

[14] Aresta, M., Dibenedetto, A., Angelini, A. (2013) The changing paradigm in $\mathrm{CO}_{2}$ utilization. J. $\mathrm{CO} 2$ Util., 3-4: 65-73. https://doi.org/10.1016/j.jcou.2013.08.001

[15] Jia, G., Tan, Y., Han, Y. (2006). A comparative study on the thermodynamics of dimethyl ether synthesis from $\mathrm{CO}$ hydrogenation and $\mathrm{CO}_{2}$ hydrogenation. Ind. Eng. Chem. Res., 45(3): 1152-1159. https://doi.org/10.1021/ie050499b

[16] An, X., Zuo, Y.-Z., Zhang, Q., Wang, D., Wang, J.-F. (2008). Dimethyl ether synthesis from $\mathrm{CO}_{2}$ hydrogenation on a $\mathrm{CuO}-\mathrm{ZnO}-\mathrm{Al} 2 \mathrm{O} 3-\mathrm{ZrO} 2 / \mathrm{HZSM}-5$ bifucntional catalyst. Ind. Eng. Chem. Res., 47(17): 6547-6554. https://doi.org/10.1021/ie800777t

[17] Bourzutschky, J.A., Homs, N., Bell, A.T. (1990). Hydrogenation of $\mathrm{CO}_{2}$ and $\mathrm{CO}_{2} / \mathrm{CO}$ mixtures over copper-containing catalysts. J. Catal., 124(1): 73-85. https://doi.org/10.1016/0021-9517(90)90104-R

[18] Brown, D.M., Bhatt, B.L., Hsiung, T.H., Lewnard, J.J., Waller, F.J. (1991). Novel technology fior the synthesis of dimethyl ether from syngas. Catal. Today, 8(3): 279304. https://doi.org/10.1016/0920-5861(91)80055-E

[19] Olah, G.A., Goeppert, A., Prakash, G.K. (2009). Chemical recycling of carbon dioxide to methanol and dimethyl ether: from greenhouse gas to renewable, environmentally carbon neutral fuels and synthetic hydrocarbons. J. Org. Chem., 74(2): 487-498. https://doi.org/10.1021/jo801260f

[20] Li, Y., Wang, T., Yin X., Wu, C., Ma, L., Li, H., Lv, Y., Sun, L. (2010). 100 t/a-scale demonstration of direct dimethyl ether synthesis from corncob-derived syngas. Ren. $\quad$ Energ., $35(3)$ : 583-587. https://doi.org/10.1016/j.renene.2009.08.002

[21] Ge, Q., Huang, Y., Qiu, F., Li, S. (1998). Bifunctional catalysts for conversion of synthesis gas to dimethyl ether. Appl. Catal. A: Gen., 167(1): 23-30. https://doi.org/10.1016/S0926-860X(97)00290-1

[22] Catizzone, E., Bonura, G., Migliori, M., Frusteri, F., Giordano, G. (2018). $\mathrm{CO}_{2}$ recycling to dimethyl ether: State-of-the-art and perspectives. Molecules, 23(1): 3158. https://doi.org/10.3390/molecules23010031

[23] Sierra, I. Erena, J., Aguayo, T., Olazar, M., Bilbao, J. (2010). Deactivation kinetics for direct dimethyl ether synthesis on a $\mathrm{CuO}-\mathrm{ZnO}-\mathrm{Al}_{2} \mathrm{O}_{3} / \gamma-\mathrm{Al}_{2} \mathrm{O}_{3}$ catalysts. Ind. Eng. Chem. $\quad$ Res., 49(2): 481-489. https://doi.org/10.1021/ie900978a

[24] Naik, S.P., Ryu, T., Bui, V., Miller, J.D., Drinnan, N., Zmierczak, W. (2011). Synthesis of DME from $\mathrm{CO}_{2} / \mathrm{H}_{2}$ gas mixture. Chem. Eng. J., 167(1): 362-368. https://doi.org/10.1016/j.cej.2010.12.087

[25] Abu-Dahrieh, J., Rooney, D., Goguet, A., Saih, Y. (2012). Activity and deactivation studies for direct dimethyl ether synthesis using $\mathrm{CuO}-\mathrm{ZnO}-\mathrm{Al}_{2} \mathrm{O}_{3}$ with NH4ZSM-5, HZSM-5 or $\gamma-\mathrm{Al}_{2} \mathrm{O}_{3}$. Chem. Eng. J., 203(1):

201-211. https://doi.org/10.1016/j.cej.2012.07.011

[26] Bonura, G., Migliori, M., Frusteri, L., Cannilla, C.,
Catizzone, E., Giordano, G. Frusteri, F. (2018). Acidity control of zeolite functionality on activity and stability of hybrid catalysts during DME production via $\mathrm{CO}_{2}$ hydrogenation. J. $\quad \mathrm{CO}_{2} \quad$ Util., 24: 398-406. https://doi.org/10.1016/j.jcou.2018.01.028

[27] Bonura, G., Frusteri, F., Cannilla, C., DragoFerrante, G., Aloise, A., Catizzone E., Migliori, M., Giordano, G. (2016). Catalytic features of CuZnZr-zeolite hybrid systems for the direct $\mathrm{CO}_{2}$-to-DME hydrogenation reaction. Catal. Today, 277: 48-54. https://doi.org/10.1016/j.cattod.2016.02.013

[28] Catizzone, E., Migliori, M., Purita, A., Giordano, G. (2019). Ferrierite vs. $\gamma-\mathrm{Al}_{2} \mathrm{O}_{3}$ : the superiority of zeolites in terms of water-resistance in vapour-phase dehydration of methanol to dimethyl ether. J. Energ. Chem., 30 : 162-169. https://doi.org/10.1016/j.jechem.2018.05.004

[29] Migliori, M., Catizzone, E., Aloise, A., Bonura, G., Gomez-Hortiguela, L., Frusteri, L., Cannilla, C., Frusteri, F., Giordano, G. (2018). New insights about coke deposition in methanol-to-DME reaction over MOR-, MFI- and FER-type zeolites. J. Ind. Eng. Chem., 68: 196-208. https://doi.org/10.1016/j.jiec.2018.07.046

[30] Guisnet, M., Magnoux, P. (1989). Coking and deactivation of zeolites: influence of the pore structure. Appl. Catal., $\quad$ 54(1): 1-27. https://doi.org/10.1016/S0166-9834(00)82350-7

[31] Derouane, E.G. (1985). Factor affecting the deactivation of zeolites by coking. Stud. Surf. Sci. Catal., 20: 221240. https://doi.org/10.1016/S0167-2991(09)60173-7

[32] Corma, A. (1995). Inorganic solid acids and their use in acid-catalyzed hydrocarbon reactions. Chem. Rev., 95: 559-614. https://doi.org/10.1021/cr00035a006

[33] Corma, A. (2003). State of the art and future challenges of zeolites as catalysts. J. Catal., 216(1-2): 298-312. https://doi.org/10.1016/S0021-9517(02)00132-X

[34] Catizzone, E., Migliori, M., Aloise, A., Lamberti, R., Giordano, G. (2019). Hierarchical low $\mathrm{Si} / \mathrm{Al}$ ratio ferrierite zeolite by sequential postsynthesis treatment: catalytic assessment in dehydration reaction of methanol. J. Chem., https://doi.org/10.1155/2019/3084356

[35] Catizzone, E., Van Daele, S., Bianco, M., Di Michele, A., Aloise, A. Migliori, M., Valtchev, V. Giordano, G. (2019). Catalytic application of ferrierite nanocrystals in vapour-phase dehyrdation of methanol to dimethyl ether. Appl. Catal. B.: Env., 243: 273-282. https://doi.org/10.1016/j.apcatb.2018.10.060

[36] Prasad, P.S., Bae, J.W., Kang, S.-H., Lee, Y.-J., Jun, K.W. (2008). Single-step synthesis of DME from syngas on $\mathrm{Cu}-\mathrm{ZnO}-\mathrm{Al}_{2} \mathrm{O}_{3}$ /zeolite bifunctional catalysts: The superiority of ferrierite over the other zeolites. Fuel Process. Technol., 89(12): 1281-1286. https://doi.org/10.1016/j.fuproc.2008.07.014

[37] Catizzone, E., Aloise, A., Migliori, M., Giordano, G. (2017). From 1-D to 3-D zeolite structures: performance assessment in catalysis of vapour-phase methanol dehydration to DME. Microp. Mesopo. Mater., 243: 102-111. https://doi.org/10.1016/j.micromeso.2017.02.022

[38] Centi, G., Perathoner, S., Pino, F., Arrigo, R., Giordano, G., Katovic, A., Pedulà, V. (2005). Performances of Fe[Al, B]MFI catalysts in benzene hydroxylation with $\mathrm{N}_{2} \mathrm{O}$ : The role of zeolite defects as host sites for highly 
active iron species. Catal. Today, 110(3-4): 211-220. https://doi.org/10.1016/j.cattod.2005.09.041

[39] Campelo, J.M., Lafont, F., Marinas, J.M., Ojeda, M. (2000). Studies of catalyst deactivation in methanol conversion with high, medium and small pore silicoaluminophosphates. Appl. Catal. A., 192(1): 85-96. https://doi.org/10.1016/S0926-860X(99)00329-4

[40] Bonura, G., Cannilla, C., Frusteri, L., Mezzapica, A., Frusteri, F. (2017). DME production by $\mathrm{CO}_{2}$ hydrogenation: key factors affecting the behaviour of CuZnZr/ferrierite catalysts. Catal. Today, 281(1): 337344. https://doi.org/10.1016/j.cattod.2016.05.057
[41] Ordomsky, V.V., Cai, M., Sushkevich, V., Moldovan, S., Ersen, O., Lancelot, C., Valtchev, V., Khodakov, A.Y. (2014). The role of external acid sites of ZSM-5 in deactivation of hybrid CuZnAl/ZSM-5 catalyst for direact dimethyl ether synthesis from syngas. Appl. Catal. A: Gen., 486: 266-275. https://doi.org/10.1016/j.apcata.2014.08.030

[42] Niwa, M., Katada, N. (2013). New method for the temperature-programmed desorption (TPD) of ammonia experiment for characterization of zeolite acidity: A review. The Chemical Record, 13(5): 432-455. https://doi.org/10.1002/tcr.201300009. 